\title{
EXPOSURE TO ULTRASOUND DECREASES THE RECALCIFICATION TIME OF PLATELET RICH PLASMA
}

\author{
A. R. WILLIAMS* and W. D. O'BRIEN, JR. $\dagger$ \\ Division of Biological Effects, Bureau of Raiological Health, Food and Drug Administration, Rockville. MD 20852. \\ U.S.A. \\ and
}

B. S. COLLER

Hematology Service, Clinical Center, National Institutes of Health, Bethesda, MD 20014, U.S.A.

(First received 26 May 1975; and in final form 5 August 1975)

\begin{abstract}
Human blood was withdrawn, anticoagulated with citrate, and centrifuged, yielding platelet rich plasma (PRP). Recalcification times (i.e. the time taken to form a clot following the addition of sufficient calcium ions) were measured with a semiautomatic device. There were no changes in the recalcification time of PRP sample immediately following exposure to continuous wave $1 \mathrm{MHz}$ ultrasound at intensities in the range $0.065-2 \mathrm{~W} / \mathrm{cm}^{-2}$. However. subsequent measurements showed an irreversible time dependent decrease of the recalcification time of an asymptotic value which was invariably less than that of the controls. This behavior can be interpreted as a time dependent alteration to the platelet population.
\end{abstract}

Key words: Acoustics, Blood, Blood coagulation, Blood platelets, Blood coagulation factors, Blood coagulation tests, Ultrasonics, Ultrasonic therapy.

\section{INTRODUCTION}

The hemostatic mechanism in man is intimately involved with the normal function of the blood platelets. Following vascular injury there is immediate, but transient, vascular contraction (Quick, 1969). A "hemostatic plug" is then formed by platelet adhesion to exposed subendothelial connective tissues and the subsequent aggregation and adhesion of new platelets to give a "white thrombus" (Thomas, 1972). Biochemical changes at or near the platelet surface, while it is participating in plug formation, accelerate the plasma coagulation system to form a fibrin network which stabilizes the white thrombus and enables it to grow by incorporation of red cells, white cells and more platelets giving a true clot (Stormorken and Owren, 1971).

When platelets adhere to one or more of the subendothelial structures, particularly collagen, they actively expel the contents of some of their granules (Spaet and Stemerman, 1972) in what is commonly called the "platelet release reaction" (Holmsen, 1972; Holmsen et al., 1973; Sack, 1973). Two of the released granule components, namely, adenosine diphosphate (ADP) and 5-hydroxy tryptamine (serotonin), are platelet aggregating agents and, in the presence of calcium and fibrinogen, cause neighboring platelets to undergo morphological changes and attach themselves to other platelets where they in turn undergo their own release reaction (Born, 1972).

The plasma coagulation system which is responsible for fibrin formation is extremely complex and not entirely understood. Briefly, it consists of a series of inactive "clotting factors" which may be conceptually arranged in a cascade or waterfall pattern such that activation of one factor causes activation of the next factor down the chain.

*Present address: Depts. of Anatomy and Medical Biophysics, University of Manchester, Manchester, U.K.

tPresent address: Bioacoustics Research Laboratory University of Illinois, Urbana, IL 61801, U.S.A.
Provided that all necessary factors and cofactors are present, activation leads to the conversion of prothrombin to thrombin, which in turn converts fibrinogen to fibrin (Bennett and Douglas, 1973; Seegers, 1973). Fibrin formation in vitro is greatly accelerated by the availability of a clot promoting factor called platelet factor 3 (PF-3). PF-3 is a general term describing a heterogeneous population of phospholipids found within the secretory granules and non-vesicular membranes of intact platelets (Aggeler et al., 1971). When made available, PF-3 is believed to act as a miceller catalytic surface for the activation and interaction of some of the protein clotting factors (Surgenor and Wallach, 1961). While apparently not identical phenomena, the release reaction and increased PF-3 availability often occur together.

Glover et al. (1974) showed that fresh human platelets in platelet rich plasma (PRP) undergo a release of secretory granule components, including serotonin, ADP and adenosine monophosphate (AMP), when subjected to a hydrodynamic shear stress to $100-150 \mathrm{dyn} / \mathrm{cm}^{2}$ for $5 \mathrm{~min}$ at room temperature. These samples, which were sheared in a couette-cylinder apparatus having cone and plate geometry at its base and cone-in-cone geometry at its top (MacCallum et al., 1973), also exhibited increased "available" PF-3 activity as evidenced by a shortened recalcification time (Glover et al., 1974). Electron microscopic examination of the sheared platelets showed organelle centralization and a decrease in the average number of secretory granules. He interpreted this to mean that the platelet release reaction had occurred as a result of the application of shear stress. Lemuth (1973) exposed platelets to shear stress and obtained enzyme release threshold values of $150-200 \mathrm{dyn} / \mathrm{cm}^{2}$ following a $2 \mathrm{~min}$ exposure. Similar results were obtained by Hung et al. (1974) who found a shear stress threshold of approx. $180 \mathrm{dyn} / \mathrm{cm}^{2}$ for the instantaneous rupture of the most sensitive platelets in a couette cylinder apparatus (Sutera et al., 1972).

Large hydrodynamic shear stresses are developed in 
the acoustic microstreaming field generated close to the surface of small gas-filled bubbles pulsating radially in a low amplitude ultrasound field, i.e. "stable" cavitation (Nyborg, 1968). A transversely oscillating steel wire has been used to mimic this oscillatory bubble behavior (Williams et al., 1970). In this system serotonin was released from fresh human platelets at very low wire displacement amplitudes corresponding to hydrodynamic shear stresses of about $130 \mathrm{dyn} / \mathrm{cm}^{2}$ (Williams, 1974).

In view of the above reports, it is reasonable to expect that large hydrodynamic shear stresses (e.g. any of the various forms of ultrasonic cavitation) could cause a disturbance of the most shear susceptible platelets leading to the release reaction and increased PF-3 availability. This, in turn, could either induce platelet aggregation or accelerate blood coagulation. To test this hypothesis, fresh human PRP was exposed to ultrasound at intensity levels within the current therapeutic and diagnostic range (Hill, 1969; Lehmann and Guy, 1972). Changes in coagulation dynamics were measured using recalcification time as an index of the rate of fibrin formation.

\section{METHODS AND MATERIALS}

Blood $(20 \mathrm{ml})$ was withdrawn from healthy adult volunteers by an experienced technician under the direction of a physician via an antecubital vein into disposable plastic syringes and anticoagulated with $20 \%$ $\mathrm{w} / \mathrm{v}$ trisodium citrate $(0.4 \mathrm{ml})$. Within $10 \mathrm{~min}$, the blood was transferred to polycarbonate centrifuge tubes and spun at room temperature at $1000 \mathrm{~g}$ for $5 \mathrm{~min}$ to sediment the erythrocytes. The supernatant (approx. $7-9 \mathrm{ml}$ of platelet rich plasma, PRP) was removed with a siliconized pasteur pipette and placed into another polycarbonate tube which was gently inverted for $30 \mathrm{sec}$ at $5 \mathrm{~min}$ intervals to prevent the platelets from settling. The PRP was left at room temperature $\left(21-23^{\circ} \mathrm{C}\right)$ for $\mathrm{ca} .1 \mathrm{hr}$ before recalcification time measurements were performed; this procedure greatly increased the reproducibility of the measurements (see Discussion).

Recalcification time of PRP (i.e. the time taken to form a fibrin clot following the addition of excess calcium ions) was measured using a Fibrometer (BBL, BioQuest, Cockeysville, Maryland, USA) fitted with a $0.4 \mathrm{ml}$ capacity probe. Isotonic saline $\left(0 \cdot 1 \mathrm{ml}\right.$ at $\left.37^{\circ} \mathrm{C}\right)$ was placed in the prewarmed plastic reaction vessel and PRP $(0.1 \mathrm{ml}$ at room temperature) was added; after gentle mixing $0.025 \mathrm{M} \mathrm{CaCl}_{2}\left(0.2 \mathrm{ml}\right.$ at $\left.37^{\circ} \mathrm{C}\right)$ was added, the probe positioned and the timer started. The probe contains two electrodes which drop into the $0.4 \mathrm{ml}$ mixture. The moving electrode cycles in and out of the fluid with its maximum upper excursion $1.25 \mathrm{~mm}$ above the fluid surface while the stationary electrode always remains in the test mixture. At the upper position, the electrical impedance between the moving and stationary electrodes is sampled. As the moving electrode passes through the fluid, any fibrin strands which are formed are caught at its tip. This then maintains electrical contact with the fluid surface which in turn alters the sampled impedance and stops the timer. Under the appropriate reagent conditions the reproducibility of this apparatus is $\pm 2 \%$ or better, and it is widely used for many clinical and diagnostic procedures (Miale, 1965).

Whole blood recalcification time was determined by the BART test (Blood Activated Recalcification Time reagent, BBL Ltd., Cockeysville, MD, U.S.A.). The BART reagent contains a surface active reagent, diatomaceous silicate, which maximizes PF-3 availability. After the whole blood was exposed to ultrasound, a sample $(0.2 \mathrm{ml})$ was placed into the fibrometer plastic reaction vessel. After one minute to allow the blood to reach $37^{\circ} \mathrm{C}$, the BART reagent $\left(0.2 \mathrm{ml}\right.$ at $\left.37^{\circ} \mathrm{C}\right)$ was added and the timer started.

Replicate control measurements of the recalcification time were made and plotted as a function of the chronological time after blood drawing until a linear trend with only a minimal slope was observed. At this point an aliquot of the PRP was exposed to ultrasonic irradiation as described below, the chronological time noted and the sample transferred to a polycarbonate tube similar to that of the control. Replicate measurements were made of the recalcification times of both control and irradiated samples as a function of chronological time.

The ultrasonic exposures were performed by carefully transferring approx. $1.5 \mathrm{~cm}^{3}$ of PRP from the control sample into a cylindrical Pyrex ${ }^{(R)}$ glass vessel $(1 \cdot 1 \mathrm{~cm}$ i.d. and $1.5 \mathrm{~cm}$ long) with a siliconized pasteur pipette. Access to the vessel was through a stem which was mounted at $90^{\circ}$ to the vessel axis and which also served to support the vessel in the ultrasonic beam (Fig. 1). Both ends of the vessel were covered with Saran Wrap ${ }^{(R)}$ and held in a taut manner by two 0-ring supports. All surfaces were siliconized to prevent surface activation of the platelets by the glass.

The vessel was positioned in the exposure tank shown in Fig. 1 in such a manner that (1) its main axis was coincident with the ultrasonic beam axis and (2) the distance from the transducer surface to the closest Saran Wrap $^{(\mathrm{R})}$ window was $2.54 \mathrm{~cm}$. The samples were exposed in the near field to simulate the exposure conditions of subdermal blood vessels which would be subjected to ultrasonic exposure from therapeutic or diagnostic devices. The temperature of the isotonic saline in the exposure tank and the castor oil absorber were controlled at $30 \pm 0.2^{\circ} \mathrm{C}$. Castor oil, separated from the isotonic saline by Saran Wrap ${ }^{|R|}$, was located at the far end of the exposure tank and served as an absorber of ultrasound and thus minimized standing waves.

The net electrical power to the $3.8 \mathrm{~cm}$ dia., $1 \mathrm{MHz}$ fundamental thickness mode, PZT- $4^{(\mathrm{R})}$ transducer, mounted in a stainless steel holder, was monitored by a dual directional coupler. The efficiency of the transducer assembly (net electrical power converted to ultrasonic

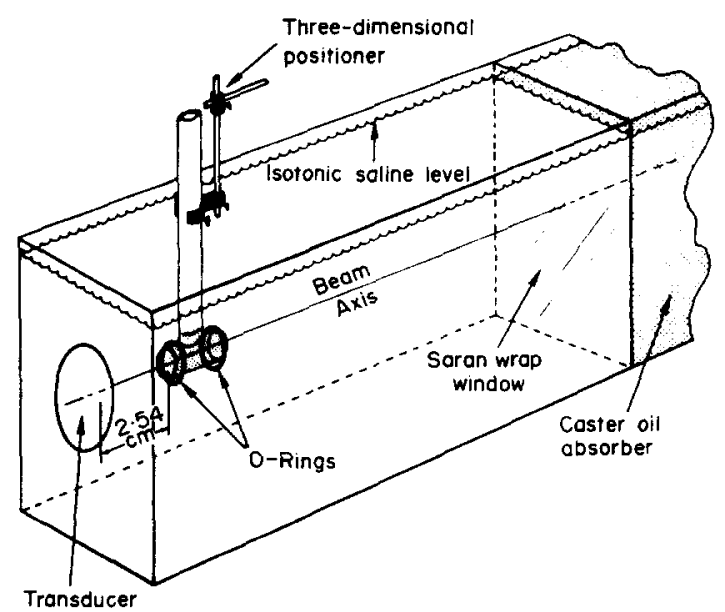

Fig. 1. Schematic view of the ultrasonic exposure tank demonstrating the position of the cylindrical Pyrex ${ }^{(k)}$ glass vessel. The shaded area within the vessel represents the volume occupied by the PRP. 
power) was determined by the bouyant float method (Stewart et al., 1973: O'Brien et al., 1974).

Beam plots of the ultrasonic field were made at $2.54 \mathrm{~cm}$ from the transducer surface with a miniature ultrasonic hydrophone (Colbert et al., 1972) to determine intensity distribution. The $3 \mathrm{~dB}$ width of the ultrasonic intensity at $2.54 \mathrm{~cm}$ from the transducer surface was $1.8 \mathrm{~cm}$ and the ultrasonic intensity over the $1.1 \mathrm{~cm}$ dia. $\left(\right.$ area $\left.=0.95 \mathrm{~cm}^{2}\right)$ of the vessel's Saran Wrap ${ }^{(R)}$ window was uniform to 1.8 dB. All reported ultrasonic intensities (accuracy $\pm 15 \%$; reproducibility $\pm 5 \%$ ) represent what the spatially averaged intensity over the irradiation vessel's Saran Wrap ${ }^{i R}$ window would be at $2.54 \mathrm{~cm}$ from the transducer surface but without the vessel in place. See O'Brien et al. (1974) for further equipment and dosimetric details. Recalcification times of PRP from the same donor which was placed in the irradiation chamber and immersed in the water bath for $6 \mathrm{~min}$ (one minute for positioning and five minutes for exposing), but not exposed to ultrasonic energy (i.e. sham irradiated) are also obtained.

PRP samples $(0.7 \mathrm{ml})$ were exposed to hydrodynamic shear stress in a Ferranti-Shirley cone and plate viscometer. The samples were maintained at $25 \pm 0 \cdot 3^{\circ} \mathrm{C}$ by contact with the stationary water cooled plate and subjected to a uniform shear stress in laminar flow of $235 \pm 5 \mathrm{dyn} / \mathrm{cm}^{2}$ (at a velocity gradient of $1.714 \times 10^{4} / \mathrm{sec}$ ) for $5 \mathrm{~min}$. The sheared PRP was removed with a plastic syringe, transferred to a polycarbonate tube and recalcifcation time measurements performed as described above.

\section{RESLLTS}

Figure 2 shows typical replicate recalcification times for control and sham irradiated PRP (female donor 1) as a function of chronological time. The results from sham irradiated specimens show that irradiation chamber did not significantly change the coagulation behavior of the PRP.

Figure 3 demonstrates the effect of ultrasonic exposure on the recalcification time (female donor 2). Curve $A$ represents a $5 \mathrm{~min}$ exposure at $1.6 \mathrm{~W} / \mathrm{cm}^{2}$ and curve B represents a $5 \mathrm{~min}$ exposure at $0.33 \mathrm{~W} / \mathrm{cm}^{2}$. There was no measurable change in the recalcification time of the PRP immediately following irradiation, but subsequent replicate measurements showed a transient increase followed by a decrease in the recalcification times which eventually reached an asymptotic value which was invariably less than that of the control. These asymptotic values remained less than that of the control for at least $4 \mathrm{hr}$ when the PRP was kept at $22^{\circ} \mathrm{C}$.

Figure 4 shows similar results obtained with PRP from female donor 1. Chronologically, data in Fig. 4 is a continuation of that in Fig. 2. Curve A represents a $5 \mathrm{~min}$ exposure at $0.065 \mathrm{~W} / \mathrm{cm}^{2}$ and curve $B$ represents a $5 \mathrm{~min}$ exposure at $0.33 \mathrm{~W} / \mathrm{cm}^{2}$. These results are similar to those of Fig. 3 in that there was no measurable change in the recalcification time of the PRP immediately following irradiation and there was a time dependent decrease in the recalcification time to an asymptotic value which was less than that of the controls. However, the results in Fig. 4 differ from those presented in Fig. 3 in that there was no transient increase in the recalcification time preceding the decrease to the asymptotic value.

Curve $4 \mathrm{~A}\left(0.065 \mathrm{~W} / \mathrm{cm}^{2}\right)$ reached an asymptotic value which was approx. $9 \%$ less than the control value while curves $3 B$ and $4 B$ (both $0.33 \mathrm{~W} / \mathrm{cm}^{2}$ ) gave values which were 20 and $22 \%$ less. respectively. However. curve $3 \mathrm{~A}$, which received the highest exposure. $\left(1.6 \mathrm{~W} / \mathrm{cm}^{2}\right)$ gave a decrease of only $16 \%$. Other samples showed similar decreases to an asymptotic value following irradiation, but they also gave a marked variability in the magnitude of the response. In view of our small sample numbers to date (ten), it is not possible to determine whether or not this variability is due to biological variables within each sample or to physical variables (e.g. "cavitation") associated with the irradiation procedure.

To investigate the system under maximum $\mathrm{PF}-3$ release conditions, so as to minimize any further effect of uitrasound on PF-3 availability. the BART test was performed. Figure 5 presents the superimposed results obtained with two adult male donors. The open circles and crosses represent control measurements for the two donors, while the symbols enumerated in the Figure legend show the effect of $5 \mathrm{~min}$ irradiation at $0 \cdot 33.0 \cdot 80$, 2.0 and $4.0 \mathrm{~W} / \mathrm{cm}^{2}$. It can be seen that ultrasonic

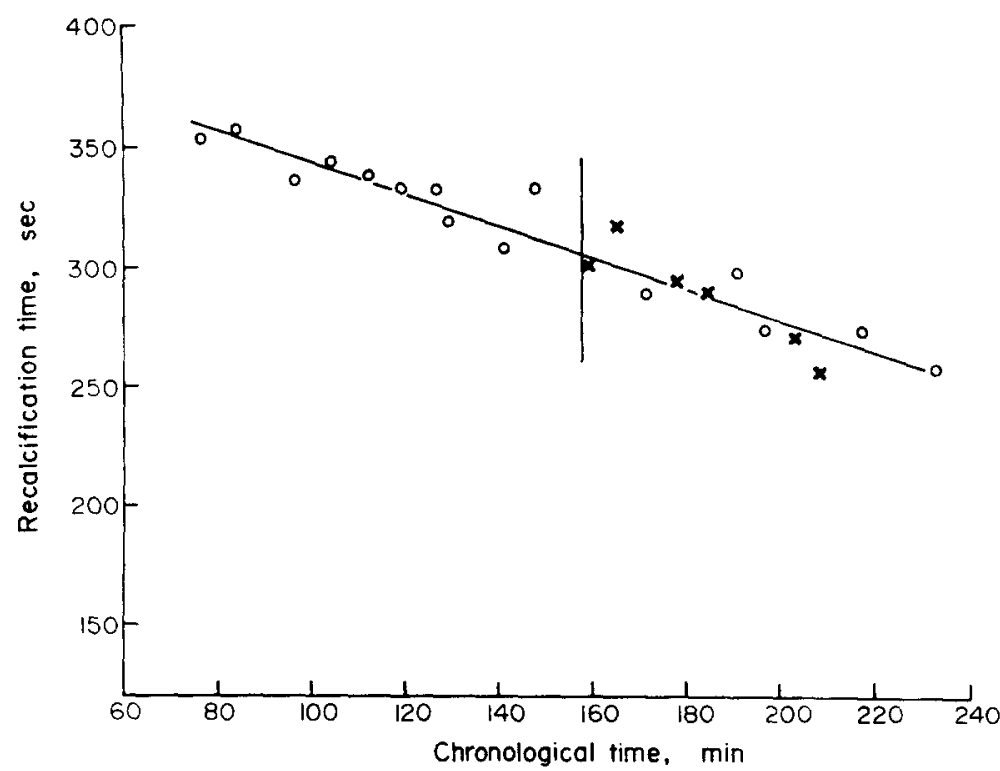

Fig. 2. Recalcification time of PRP from female donor 1 as a function of chronological time following withdrawal for control $O$ ) and sham $(x)$ irradiated samples. Vertical line represents removal of samples from saline bath. 


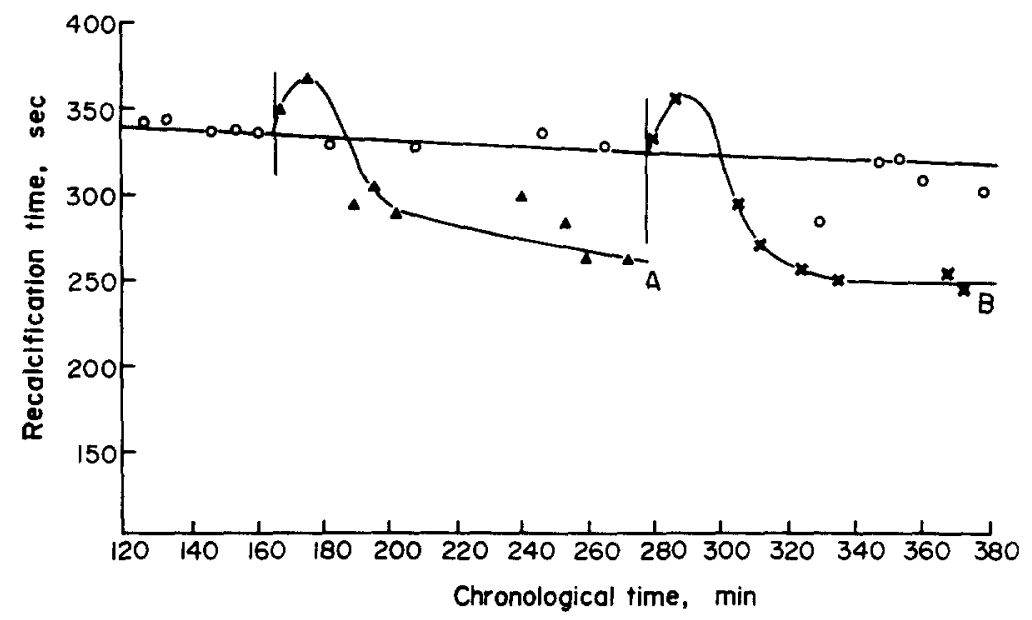

Fig. 3. Recalcification time of PRP from female donor 2 as a function of chronological time following withdrawal. Curve $A(\Delta)$ represents $1.6 \mathrm{~W} / \mathrm{cm}^{2}$ and curve $B(x)$ represents $0.33 \mathrm{~W} / \mathrm{cm}^{2}$, both exposed for $5 \mathrm{~min}$. Vertical lines represent the times at which each irradiation was terminated.

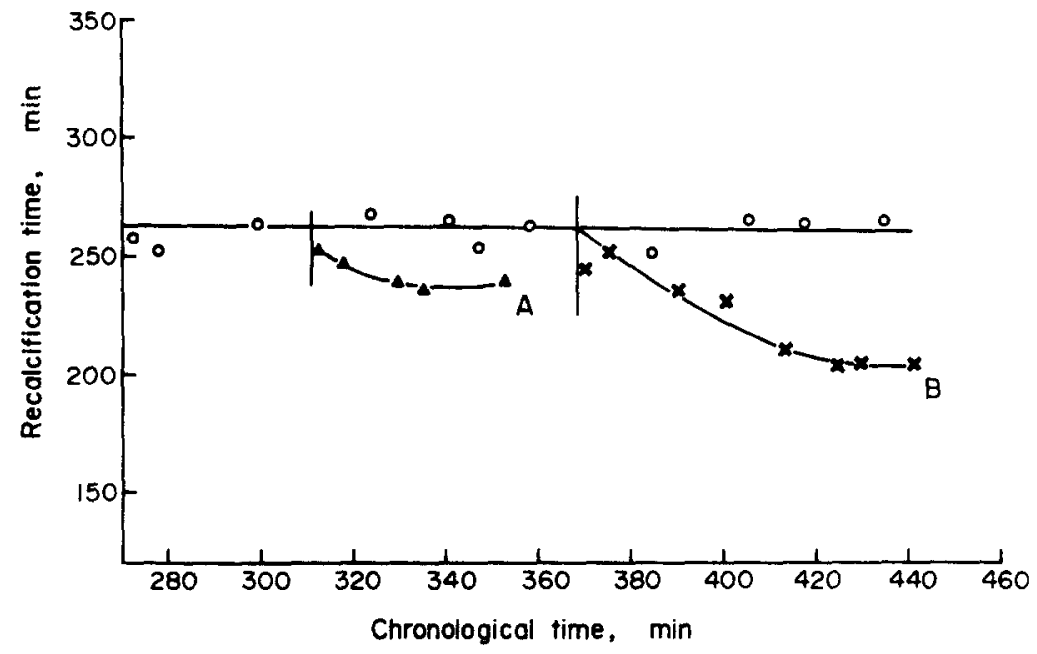

Fig. 4. Recalcification time of PRP from female donor 1 as a function of chronological time following withdrawal. Curve $(\Delta)$ represents $0.065 \mathrm{~W} / \mathrm{cm}^{2}$ and curve $B(x)$ represents $0.33 \mathrm{~W} / \mathrm{cm}^{2}$, both exposed for $5 \mathrm{~min}$. Vertical lines represent he times at which each irradiation was terminated. Chronologically, this is a continuation of Fig. 2 .

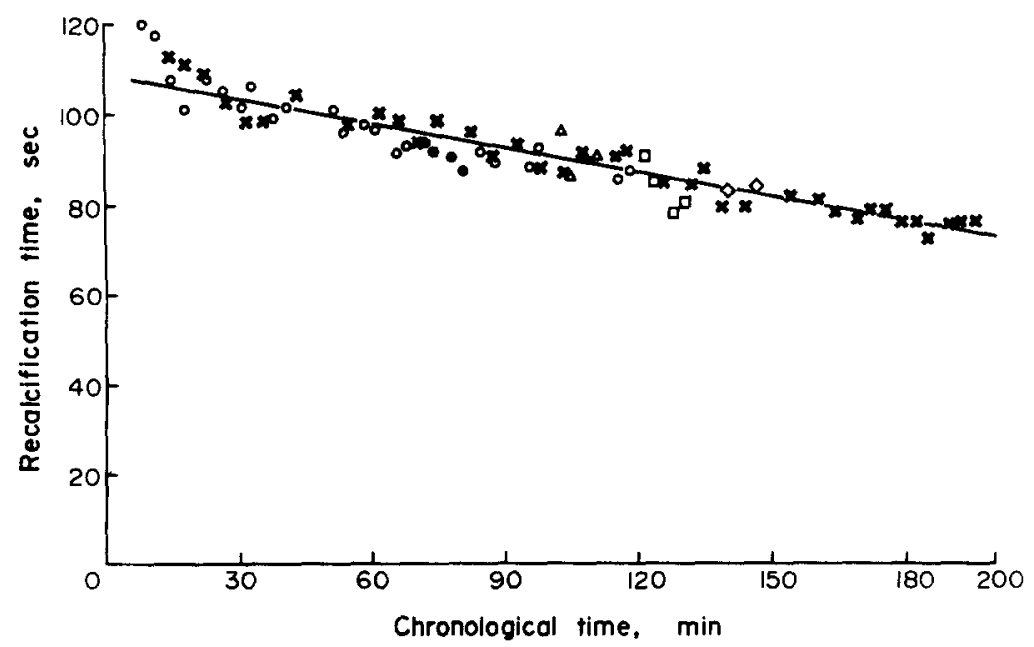

Fig. 5. BART recalcification time of PRP from male donors 1 (Control, $x$ ) and 2 (Control, $0 ; 0.33 \mathrm{~W} / \mathrm{cm}^{2}$, $0.80 \mathrm{~W} / \mathrm{cm}^{2}, \Delta, 2 \mathrm{~W} / \mathrm{cm}^{2}, \diamond ;$ all exposed for $5 \mathrm{~min}$ ) as a function of chronological time following withdrawal. 
irradiation had no measurable effect on the rate of blood coagulation as measured by the BART test, even under conditions where transient or collapse-type cavitation activity had been present (vigorous motion was visible inside the sample irradiated at $4.0 \mathrm{~W} / \mathrm{cm}$, and significant lysis of erythrocytes was observed). withdrawn; $300 \pm 20 \mathrm{sec}$ after $100 \mathrm{~min} ; 250 \pm 14 \mathrm{sec}$ after $150 \mathrm{~min}$ and $238 \pm 6 \mathrm{sec}$ after $250 \mathrm{~min}$. This behavior probably reflects either the spontaneous increase in availability of PF-3 or the activation of factor XII with time (Hirschman and Shulman, 1972; Williams, 1974) and is compatible with changes in platelet aggregation noted

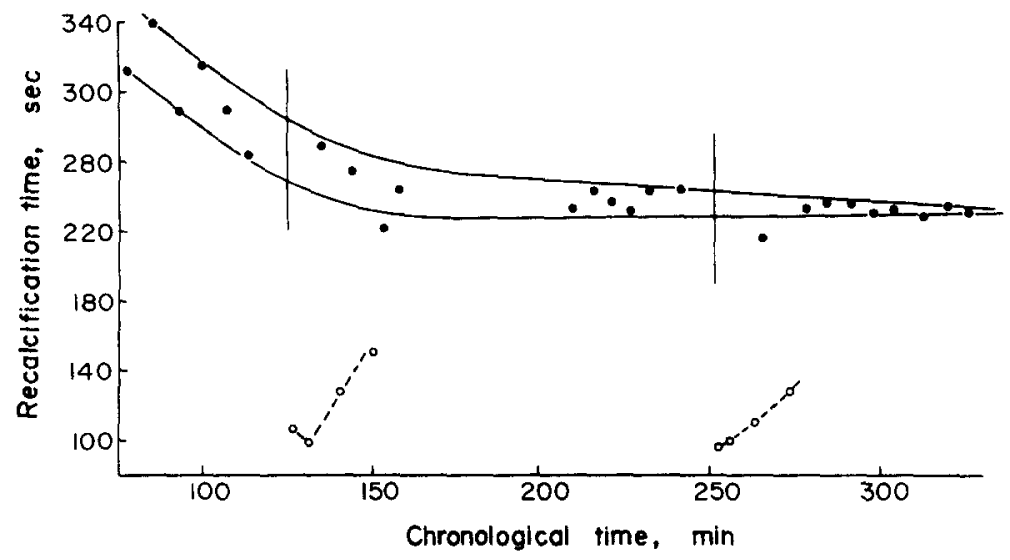

Fig. 6. Recalcification time of PRP from male donor 1 (Control, 9 ; exposed, $O$ ) as a function of chronological time following withdrawal. The vertical lines represent the times at which the samples of PRP were removed from the viscometer. Both samples were exposed to a hydrodynamic shear stress of $235 \pm 5 \mathrm{dyn} / \mathrm{cm}^{2}$ for $5 \mathrm{~min}$ at $25^{\circ} \mathrm{C}$.

Figure 6 shows the effect of prolonged exposure to hydrodynamic shear stress in a cone and plate viscometer $\left(235 \pm 5 \mathrm{dyn} / \mathrm{cm}^{2}\right.$ for $5 \mathrm{~min}$ at $\left.25^{\circ} \mathrm{C}\right)$ on the recalcification time of PRP (male donor 3). In contrast to Figs. 3 and 4, the recalcification time was decreased by ca. $60 \%$, immediately following exposure to shear stress, and was followed by a time-dependent recovery which eventually merged with the control measurements.

\section{DISCUSSION}

Care was taken to traumatize blood samples as little as possible during collection and preparation of PRP so that control platelets would not be stimulated to undergo the release reaction and minimal surface activation of the intrinsic coagulation scheme would occur. Consequently, the PRP samples gave long recalcification times (up to $450 \mathrm{sec}$ ) and in some cases the times of the control values were reproducible only to within $\pm 40 \mathrm{sec}$. In general, the longest times and the great scatter were found with PRP prepared from adult male blood, while that from females of reproductive age taking oral contraceptive agents, as determined through a physician, gave the shortest times and the best reproducibility (e.g. $260 \pm 4 \mathrm{sec}$ ). These observations are consistent with those of Renand and Gautheron (1973) who showed that platelet poor plasma (PPP) prepared from pregnant women and rats after slow speed centrifugation had the same recalcification times as their non-pregnant controls. However, PPP prepared by centrifugation at higher speeds yielded recalcification times that were considerably less than their controls for the pregnant blood samples and also for women and rats taking oral contraceptives. These authors indicated that PF-3 activity had been released from these intact platelet following minimal trama.

In general, the measured coagulation times decreased as a function of the time the PRP remained at room temperature $\left(21-23^{\circ} \mathrm{C}\right)$. Also, the reproducibility of replicate measurements improved with time, e.g. one sample of PRP from male donor 3 (Fig. 6) gave $350 \mathrm{sec}$ with a scatter of $\pm 30 \mathrm{sec} 50 \mathrm{~min}$ after the blood was as a function of the time after venepuncture (Warlow et al., 1974). It was found that PRP from females taking oral contraceptives (Figs. 2-4), incubated $100 \mathrm{~min}$ at room temperature yielded reproducible results. Pipetting PRP into and out of the irradiation vessel caused no immediate or delayed change in its recalcification time (Fig. 2). However, when portions of this same PRP sample were irradiated with ultrasound changes in recalcification time were noted (Fig. 4).

Figures 3 and 4 show representative examples of the effect of ultrasonic irradiation on the coagulation system. Every irradiation performed to date has shown no immediate change in the coagulation properties of the PRP, followed by a time-dependent decrease to some asymptotic value which was invariably less than that of the controls. Some samples, however, demonstrated a transient increase in their coagulation time before descending to their asymptote. This increase persisted for 5-20 min and, because of the limited number of samples, could not be correlated with the donor, sex or oral contraceptive use.

On the basis of our results to date, it not possible to make a positive statement as to the presence or absence of a repeatable dose-effect relationship for the observation shown in Figs. 3 and 4.

Figure 5 shows that ultrasonic irradiation had no effect on the BART time in PRP obtained from male donors. The BART reagent contains diatomaceous silicate as a surface active agent which makes an excess of PF-3 available and renders the sample insensitive to additions of more PF-3. This suggests that ultrasound accelerates the recalcification time of citrated PRP by increasing the availability of PF-3, since additional small quantities of PF-3 released following ultrasonic irradiation would have no measurable effect in the presence of the BART reagent. Also, it demonstrates that ultrasound does not cause the release or activation of any component further down in the coagulation cascade since one would anticipate that this would give a decreased BART time.

Figure 6 demonstrates the effect of prolonged exposure 
to hydrodynamic shear stress in laminar flow $(5 \mathrm{~min}$ at $235 \pm 5 \mathrm{dyn} / \mathrm{cm}^{2}$ at $25^{\circ} \mathrm{C}$ ) on the recalcification time of citrated PRP. It can be seen that, in contrast to samples exposed to ultrasound (Figs. 3 and 4), the coagulation time was decreased to its minimum value immediately upon removal of the sample from the viscometer. Subsequent measurements showed a time-dependent recovery which eventually merged with the control measurements after passing through a "refractory" phase (not shown). This behavior can be interpreted as large-scale induction of the platelet release reaction by the applied shear stress giving the immediate large decrease in the coagulation time.

Comparison of Figs. 3 and 4 with Fig. 6 shows that ultrasound did not cause immediate large-scale release of platelet factor 3 activity. Our current hypothesis is that one or more forms of cavitation-like activity had occurred (Williams et al., 1975), causing the release of PF-3 and other factors (ADP epinephrine, etc.) from that small fraction of the platelet population which was within the sphere of influence of each of the cavitation events (William, 1974), This small quantity of PF-3 was apparently not enough to significantly change the measured recalcification time immediately following irradiation. However, either a recruitment phenomenon from the release factors or some time dependent platelet damaging effect of ultrasound eventually led to release of significant quantities of PF-3 activity and, hence, the time-dependent decrease in the recalcification times seen in Figs. 3 and 4.

Acknowledgements - We wish to thank all of our most generous blood donors, and the staff of Montgomery County Health Clinic (Ms. V. Stolz and Ms. J. Kranc) for their skillful venepunctures. A. R. Williams wishes to thank Mr. Harrison of Ferranti Ltd., Moston, Manchester, England and Mr. Frehling, Plainview, New York, USA for their generous advice and help with the cone and plate viscometer. We also wish to thank Mr. S. A. Andersen and Mr. B. E. Butler for their artwork and photography, respectively, and Ms. Kathy Pruett and Miss Gail Miller for numerous typings of the manuscript.

Disclaimer-The mention of commercial products, their source, or their use in connection with material reported herein is not to be construed as either an actual or implied endorsement of such products by the Department of Health, Education, and Welfare, Public Health Service, or other sponsoring organizations.

\section{REFERENCES}

Aggeler, P. M., Sahud, M. A. and Robinson, A. J. (1971) in The Platelet (Edited by Brinkhous, K. M., Shermer, R. W. and Mostofi, F. K.,) pp. 172-182. Williams \& Wilkins, Baltimore.

Bennett, B. and Douglas, A. S. (1973) Blood coagulation mechanism. Clin. Haematol. 2, 3-22.

Born, G. V. R. (1972) Current ideas on the mechanism of platelet aggregation. Ann. N.Y. Acad. Sci. 201, 4-12.

Colbert, J. R., Eggleton, R. C. and Weidner, A. J. (1972) Intensity calibration of pulsed ultrasonic beams. Interaction of $\mathrm{Ul}$ trasound and Biological Tissues, Workshop Proceedings, pp. 187-192. DHEW Publication (FDA) 73-8008 BRH/DBE 73-1.

Glover C. J., McIntire, L. V., Natelson, E. A. and Brown, C. H. III (1974) Effect of shear stress on clot structure formation. Paper presented at the Amer. Inst. Chem. Eng. Meeting, Pittsburg, Penn., 2-5 June.
Hill. C. R. (1969) Acoustic intensity measurements of ultrasonic diagnostic devices. In Proc. 1 st. World Congress on Ultrasonics Diagnosis in Medicine and SIDUO III (Edited by Bock, J. and Ossoinig, K.) , pp. 21-27. Vienna Med. Acad., Vienna.

Hirschman, R. J. and Schulman, N. R. (1972) Utilization of the platelet release reaction to measure ITP factor and platelet antibodies. Trans. Ass. Am. Physicions 85, 325-334.

Holmsen, H. (1972) The platelet: Its membrane, physiology and biochemistry. Clin. Haematol. 1, 235-266.

Holmsen, H., Østvold, A. C. and Day, H. J. (1973) Behavior of endogeneous and newiy absorbed serotonin in the platelet release reaction. Biochem. Pharmacol. 22, 2599-2608.

Hung, T. C., Sutera, S. P. and Hochmuth. R. M.. (1974) Personal communication.

Lehmann, J. F. and Guy, A. W. (1972) Ultrasound therapy. Interaction of Ultrasound and Biological Tissues. Workshop Proceedings, pp. 141-152. DHEW Publication (FDA) 73-8008 BRH/DBE 73-1.

Lemuth, R. F. (1973) A study of the effects of shearing stress on normal human blood platelets. M. S. Thesis, Biomedical Engineering Laboratories, Rice University, Houston, TX

MacCallum, R. N., O'Bannon, W., Hellums, J. D., Alfrey, C. P. and Lynch, E. C. (1973) Rheology of Biological Systems (Edited by Caselrich and Litt). C. C. Thomas, IL.

Miale, J. B. (1965) The fibrometer system for routine coagulation tests. Am. J. clin. Pathol. 43, 475-480.

Nyborg, W. L. (1968) Mechanisms for nonthermal effects of sound. J. acoust. Soc. Am. 44, 1302-1309.

O'Brien, W. D.. Jr., Christman. C. L. and Yarrow, S. (1974) Ultrasonic biological effect exposure system. In Proceedings of the 1974 Ultrasonics Symposium. Cat. No. 74 CHO 8\%-1 SU. IEEE, N.Y.

Quick, A. J. (1969) Hemostasis in surgical procedures. Surg. Gynecol. Obstetrics 128, 523-532.

Renaud S. and Gautheron, P. (1973) Role of platelet factor 3 in the hypercoagulability induced by pregnancy and oral contraceptives. Thrombosis Diathes. Haemorrh. 30, 299-306.

Sack, E. S. (1973) Studies on the blood platelet release reaction. Medicina (B. Aires) 33, 406-414.

Seegers, W. H. (1973) Blood coagulation: A cybernetic system. Ser. Haematol. 6, 549-578.

Spaet, T. H. and Stemerman, M. B. (1972) Platelet adhesion. Ann. N.Y. Acad. Sci. 201, 13-21.

Stewart, H. F. Harris, G., Robinson, R. and Garry, J. (1973) Survey of use and performance of ultrasonic therapy units in the Washington, D.C. area. Health Physics and the Healing Arts, pp. 467-472. DHEW Publication (FDA) 73-8029.

Stormorken, H. and Owren, P. A. (1971) Physiopathology of hemostasis, Seminar Hematol. 8, 3-29.

Surgenor, D. M. and Wallach, D. F. H. (1961) Blood Platelets (Edited by Johnson. S. A.. Monto, R. W.. Rebuck, J. W. and Horn, R. C., Jr.), p. 298. Little, Brown \& Co., Boston.

Sutera, S. P. Croce, P. A. and Mehrjardi, M. (1972) Hemolysis and subhemolytic alterations of human RBC induced by turbulent shear flow. Trans. Am. Soc. Artif. Int. Organs 18, 335-341.

Thomas, D. P. (1972) The platelet contribution to arterial and venous thrombosis. Clin. Haemotol. 1, 267-282.

Warlow, C., Corina, A., Ogston, D. and Douglas, A. S. (1974) The relationship between platelet aggregation and time interval after venepuncture. Thrombos Diathes. Haemorrh. 31, 133-41.

Williams, A. R. (1974) Release of serotonin from human platelets by acoustic-microstreaming. J. Acoust. Soc. Am. 56, 1640-1643.

Williams, A. R., Hughes, D. E. and Nyborg, W. L. (1970) Hemolysis near a transverseiy oscillating wire. Science 169. 871-873.

Williams, A. R., Sykes, S. M. and O'Brien, W. D., Jr. (1975) Microtubule reorganization in platelets may express PF-3 activity. Thrombos. Diathes. Haemorrh. 33, 388-392. 